\title{
ENSINO REMOTO EMERGENCIAL E O ESTÁGIO SUPERVISIONADO NOS CURSOS DE LICENCIATURA NO CENÁRIO DA PANDEMIA COVID 19
}

\section{EMERGENCY REMOTE TEACHING AND SUPERVISED INTERNSHIP IN UNDERGRADUATE TEACHER TRAINING COURSES IN THE PANDEMIC COVID 19 SCENARIO}

\section{ENSEÑANZA REMOTA DE EMERGENCIA Y PASANTÍA SUPERVISADA EN CURSOS DE FORMACIÓN DE PROFESORES EN EL ESCENARIO PANDÉMICO DE COVID 19}

\section{Ester Maria de Figueiredo Souza ${ }^{1}$ Lúcia Gracia Ferreira²}

\begin{abstract}
Resumo: Este artigo aborda o estágio supervisionado nas licenciaturas no contexto da COVID-19. A esse componente dos projetos pedagógicos dos cursos são atribuídas carga horária obrigatória e concepção de profissionalização. As funções sociais do professor em formação inicial moldam seu exercício profissional futuro, sendo essas realizadas no conjunto de práticas de ensino, de pesquisa e de extensão. $O$ estágio curricular obrigatório, na ênfase do ensino, configura-se no exercício da docência na Educação Básica. Assim, propõem-se reflexões sobre sua realização como ensino remoto. Trata-se de um artigo decorrente de reflexões enquanto professoras de licenciatura e análise de proposta de reorganização curricular de 2002 até a atual adoção do ensino remoto tanto na Educação Básica quanto Superior. Como resultados, apresenta-se a etnografia virtual como uma das composições curriculares que preservam o estágio supervisionado como componente da docência.
\end{abstract}

Palavras-chave: COVID-19. Docência. Estágio supervisionado. Ensino remoto. Licenciatura.

Abstract: This article addresses the supervised internship in undergraduate teacher training courses in the context of COVID-19. To this component of the courses' pedagogical projects are assigned a mandatory workload and the concept of professionalization. The social functions of the teacher in initial training forge their future professional practice, which are carried out in the set of teaching, research and extension practices. The mandatory curricular internship, in the emphasis of teaching, is configured in the exercise of teaching in Basic education. Thus, reflections on its realization as remote teaching are proposed. This is an article resulting from the reflections as teachers of

\footnotetext{
${ }^{1}$ Universidade Estadual do Sudoeste da Bahia (UESB). Vitória da Conquista, Bahia, Brasil.

${ }^{2}$ Universidade Federal do Recôncavo da Bahia (UFRB). Amargosa, Bahia, Brasil.
} 
undergraduate teacher training courses and the analysis of the proposal for curricular reorganization from 2002 until the current adoption of remote education in both Basic and Higher Education. As a result, virtual ethnography is presented as one of the curricular compositions that preserve the supervised internship as a component of teaching.

Keywords: COVID-19. Teaching. Supervised internship. Remote teaching. Undergraduate teacher training course.

Resumen: Este artículo aborda la pasantía supervisada en cursos de formación de profesores en el contexto del COVID-19. A este componente de los proyectos pedagógicos de los cursos se le asigna una carga de trabajo obligatoria y el concepto de profesionalización. Las funciones sociales del docente en la formación inicial configuran su futura práctica profesional, desarrollándose aquellas en el conjunto de prácticas docentes, investigadoras y de extensión. La pasantía curricular obligatoria, en el énfasis de la docencia, se configura en el ejercicio de la docencia en Educación Básica. Así, se proponen reflexiones sobre su realización como enseñanza a distancia. Se trata de un artículo fruto de reflexiones como docentes de cursos de formación de profesores y de análisis de la propuesta de reorganización curricular desde 2002 hasta la actual adopción de la educación a distancia tanto en Educación Básica como Superior. Como resultado, la etnografía virtual se presenta como una de las composiciones curriculares que preservan la pasantía supervisada como un componente de la docencia.

Palabras clave: COVID-19. Docencia. Pasantía supervisada. Enseñanza remota. Curso de formación de profesores.

\section{INTRODUÇÃO}

No momento em que enfrentamos uma crise sem precedentes que combina fatores sanitários e econômicos, não podemos perder de vista o direito à educação, mesmo em contextos de ameaça à vida. Encontramo-nos privados do espaço público e adotam-se medidas de isolamento e distanciamento social como estratégias para enfrentamento dessa situação.

Em uma breve linha temporária, em dezembro de 2019, a Organização Mundial da Saúde (OMS) anunciou a ocorrência de uma pneumonia de causas desconhecidas na província de WuhanChina. Um mês após, esse mesmo órgão, declarou Emergência de Saúde Pública de Importância Internacional (ESPIN) em todos os continentes. No Brasil, em fevereiro de 2020, o Ministério da Saúde declara Emergência Nacional de Saúde e, a partir daí, os efeitos suspensivos de convivência social passam a ser a diretriz para organização da vida em sociedade, primando pelas estratégias indicadas anteriormente. Como medidas solidárias de pactuação federativa, estados e municípios, no conjunto de outras medidas, editam decretos relativos à suspensão de aulas e, em março de 2020, o Ministério da Educação, por meio da portaria n 343/MEC orienta a substituição de aulas presenciais por aulas em meios digitais, enquanto perdurar a situação de pandemia da COVID-19 e, 
por conseguinte, o Conselho Nacional de Educação emite atos normativos dispondo sobre organização de calendários letivos, atividades acadêmicas e de ensino para todos os níveis e modalidades da educação.

Esse contexto, dentre os inúmeros impactos decorrentes da suspensão de aulas e de atividades presenciais, nos convoca a observar e pensar alternativas para a validação do componente estágio supervisionado nos cursos de licenciatura, à luz de estratégias que considerem as atividades formativas do ensino remoto, tanto já integrantes ao currículo do curso, ou propostas a partir da necessidade de replanejamento advinda da pandemia. Assim, nos dispomos a ressoar nossa concepção de estágio supervisionado, assentada em produção técnica científica referenciada e na análise de proposta de reorganização curricular por imposição de documentos normativos expedidos a partir do ano de 2002, pelo Conselho Nacional de Educação, até o atual Parecer CNE/CP 05/2020, esse último, específico para a realização de atividades pedagógicas não presenciais no curso da COVID-19.

Quando no início deste século, no ano de 2002, o Conselho Nacional de Educação (CNE) promulgou as resoluções ${ }^{3}$ CNE/CP 01/2002 (BRASIL, 2002) e CNE/CP/02/2002 (BRASIL, 2002a) que definiram a duração e a carga horária dos cursos de licenciatura e instituíam as Diretrizes Curriculares Nacionais para a Formação de Professores da Educação Básica, as universidades e outras instâncias atinentes ao debate sobre a formação docente defrontaram-se com a exigência de reconfigurar os projetos pedagógicos dos seus cursos de licenciatura, destacando-se o estágio supervisionado como componente curricular obrigatório, com a definição de, no mínimo, 400 horas e fluxo ao longo da duração do curso.

Em 2015, a resolução CNE/CP № 02/2015, (BRASIL, 2015) ${ }^{4}$, revogando as do ano de 2002 dentre outros aspectos, reafirma a exigência de elaboração de projetos pedagógicos para os cursos de licenciatura que superem a dicotomia entre cursos de bacharelado e cursos de licenciatura, além de realçar a compreensão da expressão Prática como Componente Curricular (PCC), o que Souza e Ferreira (2019) argumentam:

Ao longo desses anos de vigência, a Resolução CNE 02/2015, já se firmou a compreensão de que o Estágio Supervisionado se distingue da PCC, porque aquele é o componente de maior carga de profissionalização e externo ao lócus de ensino. Assim, as atividades com conotação de PCC orientam-se, conforme diretrizes legais [...] (SOUZA; FERREIRA, 2019, p.198).

\footnotetext{
${ }^{3}$ http://portal.mec.gov.br/cne/arquivos/pdf/CP022002.pdf http://portal.mec.gov.br/cne/arquivos/pdf/rcp01 02.pdf

${ }^{4}$ http://portal.mec.gov.br/index.php?option=com_docman\&view=download\&alias=17719-res-cne-cp-00203072015\&ltemid $=30192$
} 
Essa arquitetura curricular proposta deixou como saldo, ao longo dessas duas décadas, a afirmação dos cursos de licenciatura como o lócus da formação para a docência. Com as devidas ressalvas, associações, fóruns de profissionais e pesquisadores, saudaram os movimentos de fortalecimento da identidade profissional da docência como um novo marco nas políticas educacionais.

No conjunto das normativas, novos marcos legais foram assentados, como resultados das deliberações dos fóruns colegiados e sindicais. Contudo, preservou-se, na organização dos projetos pedagógicos dos cursos de licenciatura, a articulação teórica e prática para que se garantam as 400 (quatrocentas) horas de Prática como Componente Curricular (PCC) e as 400 (quatrocentas) horas de estágio curricular supervisionado, a partir do início da segunda metade do curso; e destinação de carga horária não inferior a 3.200 horas para a integralização curricular.

Assim, é neste cotejo e assentando-se nas resoluções e seu impacto do cenário pandêmico que, ao auscultar iniciativas para a validação dos currículos escolares, busca-se indiciar a oferta do estágio supervisionado nos cursos de licenciatura como condição para integralização desses, considerando-se a suspensão de aulas presenciais e a opção de adoção de ensino não presencial, por modalidade de Educação a Distância (EAD) ou ensino remoto por escolas e universidades.

A Lei de Diretrizes e Bases da Educação Nacional, LDBN 9.394/96 (BRASIL, 1996) considera a EAD como uma modalidade da educação mediada por tecnologias e realizada em ambientes virtuais. O ensino remoto é uma expressão registrada no ordenamento educacional e seu endereçamento é propício às atividades e tarefas didáticas não presenciais, o que, no contexto da emergência sanitária tornou-se uma possibilidade.

Nessa intenção, pergunta-se: é possível a oferta do estágio remoto pelos cursos de licenciatura, priorizando-se a vivência no campo de estágio, a sala de aula da educação básica? A tríade professor formador/professor supervisor/ estagiário é passível de modalizações nesse contexto de formação? Os sentidos atribuídos à profissionalização pelos licenciandos podem ser reverberados nas proposições e atividades para suplementação do estágio indicadas pelas instituições? Nesse interim, este texto organiza-se em um recorte acerca do estágio supervisionado e no nosso juízo de sua composição por meio do ensino remoto, para resguardar a vivência no espaço virtual de aprendizagem e de formação. 
Portanto diferente da maioria de outras profissões que, também, estão privadas do espaço público, a profissão docente tem uma especificidade: na sua realização, quer por meio remoto, EAD ou presencial, produz conhecimento nas interações professor e estudante.

\section{UMA RETOMADA SOBRE ESTÁGIO SUPERVISIONADO NOS CURSOS DE LICENCIATURA}

Vários autores (PIMENTA; LIMA, 2011; CARROLLO, 1997; GRANCO; GILBERTO, 2009; BARRETO; OLIVEIRA; ARAÚJO, 2015; AROEIRA, PIMENTA, 2018; PICONEZ, 2012; SANTOS; COSTA; PEREIRA, 2018; GOMES, 2011; ARAÚJO; MARTINS, 2020; ARAÚJO, 2020; SOUSA, 2016) ratificam a importância do estágio supervisionado nos cursos de licenciaturas, tomando-o como componente curricular essencial para formação de professores e reconhecem que este possibilita o contato com elementos indispensáveis para a construção da identidade profissional docente.

Desse modo, o estágio supervisionado é componente de profissionalização docente dos cursos de licenciatura e esse aspecto é circundante para se projetar uma compreensão de profissionalização atrelada às mudanças na sociedade, compondo-se novas reconfigurações da docência, a partir da introjeção de valores e sentidos atribuídos às práticas discursivas do curso de licenciatura e, a nosso ver, ao que comumente se refere ao campo de estágio.

Nesse aspecto, advogamos que o campo de estágio do professor em formação inicial são os espaços da educação básica, como se referencia nos documentos legais e, em especial a sala de aula, para o exercício da regência, prática de ensino, docência. Abdicar desse espaço, por imposição de medidas sanitárias e de preservação da vida, requer tomado de decisão que, a princípio, esgotem as possibilidades de sua realização enquanto ensino remoto, não presencial. Assim, talvez, estejamos por inserir no dicionário da educação o verbete estágio supervisionado remoto emergencial e, nesse caso, o aporte da etnografia virtual é (seria) um direcionamento para oportunizar esse outro modo de formação para a docência, nos cursos de licenciatura.

O desenho curricular, exposto em Souza (2010; 2011), ao formular disciplinas de cunho pedagógico e de profissionalização para a distribuição das 400 horas do estágio supervisionado, levou em consideração a atuação do profissional nas etapas de ensino fundamental e médio da educação básica, excluindo-se a educação infantil, por essa se redirecionar, nas suas especificidades, aos cursos de Pedagogia. Assim, se expõe:

\section{- Estágio Supervisionado I}


Estágio que focaliza a pesquisa no ensino, enfatizando a organização e planejamento da pesquisa etnográfica e a elaboração do projeto de pesquisa.

\section{-Estágio Supervisionado II}

Estágio em extensão universitária, em unidades escolares, com aplicação da dimensão etnográfica da pesquisa no cotidiano escolar.

\section{- Estágio Supervisionado III}

Estágio de regência em ensino fundamental em práticas de ensino da disciplina foco da licenciatura.

\section{- Estágio Supervisionado IV}

Estágio de regência no ensino médio em práticas de ensino da disciplina foco da licenciatura.

\section{- Estágio Supervisionado V}

Estágio de extensão comunitária em espaços formais e não formais da educação básica ou aplicação de projetos de ensino.

Souza (2010) afirma que a formação para a docência requer a humanização e mudança de perfil dos estágios até então inseridos nos projetos pedagógicos dos cursos de licenciatura e que esses, ao flexibilizar e diversificar o seu formato com as experiências de pesquisa e extensão, tendem a conferir

[...] densidade científica e formação humanística ao perfil profissiológico do futuro professor, por meio de domínio de competências e habilidades exigidas pelas práticas sociais de exercício da linguagem na sociedade e culturas inseridas nas escolas. (SOUZA, 2010, p. 89)

Souza e Martins (2012) ocuparam-se por ampliar os deslocamentos dos estágios centrados nas práticas de ensino, para a tríade ensino/pesquisa e extensão, propondo, assim, a distribuição da carga horária em atividades de integração universidade e educação básica. Concluem, na referida publicação, a formatação de proposta para o desenvolvimento dos estágios em curso de formação de professores, na licenciatura em Letras, esclarecendo que a motivação para a elaboração desse novo desenho foi o de diversificar as práticas de estágio supervisionado para e possibilitar integração formativa com componentes do currículo do curso de licenciatura. Como ratificam: "O conceito de estágio supervisionado é stricto sensu: aplicação e monitoramento da ação planejada." (SOUZA; MARTINS, 2012, p. 148). 
Essa mesma prerrogativa aplica-se em contextos não presenciais, online e remotos de aprendizagem. Assim, considera-se que o estágio na imersão da sala de aula da educação básica é um direito do licenciando, pois as tarefas de planejar, aplicar e avaliar atividades de ensino em turmas previamente designadas ao professor em formação inicial é o que lhe faculta a experiência da profissionalização. O estagiário é parte da configuração escolar. Com o professor formador e o professor supervisor do estágio, vivencia-se o ambiente pedagógico da escola e processam-se extrações de conhecimentos que impactam percepção sobre o trabalho docente. Essa ação ocupará grande parte de seu oficio de professor e os percursos de formação obrigam-se a destacar espaço para a profissionalização no ambiente natural de exercício da profissão. É no estágio no formato regência, com o desenho de professor formador/professor da educação básica/sala de aula educação básica.

A ação na sala de aula de planejamento e aplicação deste planejamento é uma relação de participação e apropriação de conhecimentos, por parte do estagiário e alunos da educação básica. Tem um lugar de destaque no processo formativo, pois é nesse estágio que o licenciado encontra o contexto natural de ensino: a aula. Essa situação de intervenção e (re) conhecimento da realidade é decisiva para o processo de reflexão da práxis educacional. O ensino, por meio da regência de classe, é uma das ações formativas do protagonismo profissional, espaço de exercício da autonomia docente e de assunção da autoridade profissional do estagiário (SOUZA, MARTINS, 2012, p.14).

A compilação das resoluções e dos trabalhos referenciados expõe a validação do componente estágio supervisionado para integralização do curso e a sua realização na diversificação de práticas para a docência, ressalvando-se a exigência de atuação no campo de trabalho da profissão, como o ilustrado do Estágio Supervisionado III e Estágio Supervisionado IV 5 . Registrar esse deslocamento do âmbito da instituição formadora para a instituição de profissionalização é uma condição singular para a compreensão e planejamento das práticas de estágio.

A vida na educação superior é tecida por meio do desejo de profissionalização, associado ao da realização pessoal. Santos e Givani $(2020$, p. 7) perspectivam que as relações sociais na organização do espaço escolar, "[...] vem a contribuir para a figuração do professor, retratando as exigências da profissão, as responsabilidades e dificuldades enfrentadas na prática."

Assim, o espaço da escola e a sala de aula, com suas configurações e sob a exploração do olhar etnográfico em relação a docência, são carregadas de um padrão hegemônico e formatado na

\footnotetext{
${ }^{5}$ Essa proposta de reconstrução curricular, ainda é vigente nos cursos de Letras da Universidade Estadual do Sudoeste da Bahia - UESB, desde 2002 e, com redimensionamentos foi implantado em outros cursos de licenciatura de instituições de educação superior.
} 
cultura escolar; padrão esse reiterado pelos professores, gestores, funcionários, estudantes e, até, pelos coletivos de responsáveis pelos estudantes. Esse padrão se constitui em objeto de investigação para conformar as práticas pedagógicas e é imprescindível a sua interpretação como tema da formação para a docência, principalmente, pelo que dele se apreende de sentidos da docência, como também pelas possibilidades que o agir docente provoca de desconstruções.

O estudante em formação inicial para a docência, ao se reconhecer como sujeito professor na escola, compõe pertencimentos a esse grupo social e (re)compõe seu percurso formativo e auto formativo. Há tensões que são assumidas pelo estagiário que, no encontro com o professor da educação básica, são transformadas em aprendizagens da docência, daí a necessária presença desse outro sujeito para se refletir e refratar a sua formação, uma vez que nos transformamos ante as responsabilidades que nos são atribuídas para o reconhecimento e o funcionamento da gestão pedagógica da escola e da própria metodologia da sala de aula Revozeamos a compreensão dialógica do constituir-se professor/ professora, transcrevendo Bortolotto e Fiad (2017):

É certo, como defende Bakhtin, que todo ato humano (nele o pedagógico) tem no seu horizonte o compromisso com outro (o aluno), tem compromisso com a verdadeira amorosidade, a dialógica. Na cultura escolar, a relação interpessoal canônica da sala de aula prevê dois sujeitos em polos distintos e hierarquicamente definidos: para aquele que ensina, o papel da autoridade (autoritarismo?); para aquele que aprende, o acatamento da autoridade do outro. Nessa perspectiva canônica estaria, ainda que subliminarmente, refletida e refratada em nossas ações cotidianas peculiares nesse espaço público escolar a tese do dialogismo em que o eu e o outro se constituem como dois centros axiológicos? Como o professor (aqui ampliamos a pergunta para além da experiência do estágio) se vê nesse processo de experiência profissional eu-outro? (BORTOLOTTO; FIAD, 2017, p.12).

Para concluir esse tópico, corroboramos que os estágios nos formatos ensino, extensão e pesquisa, como propusemos em Souza (2010), são integrantes da docência no enquadre da formação do professor da educação básica, porque se direcionam a pesquisar o ensino, o cotidiano escolar, as metodologias e práticas pedagógicas específicas das licenciaturas em curso pelos professores em formação inicial. Essa matriz confere unidade temática ao componente estágio supervisionado, sob a compreensão da docência como práticas discursivas. O que nos envolve à continuidade dessa escrita é buscar indícios que preservem a composição dos estágios no contexto de ensino remoto não presencial, argumentando que é possível a sua oferta no enfoque das práticas de ensino na sala de aula virtual, desde que mantidas as interações decorrentes dos papeis discursivos dos professor formador/professor regente/professor em formação inicial (estagiário) ou 
seja, preservando-se a tríade de articulação da educação superior com a educação básica e reconhecendo-se a instituição escola como o contexto natural de ação e reflexão sobre a práxis pedagógica e o ensino enquanto um dos objetos da docência. Desse modo, podem-se processar extrações acerca dos sentidos atribuídos à profissionalização pelos licenciandos, como indicamos na introdução deste artigo.

\section{ESTAGIO SUPERVISIONADO E ENSINO REMOTO}

Os licenciandos deparam-se com etapas constitutivas de aprendizagem da docência por meio de uma organização curricular centrada, em grande parte, nas disciplinas do núcleo pedagógico. Essa aprendizagem, para além do fluxo do curso, é, também, possibilitada pela vivência e imersão no ambiente de trabalho. São complementares os dois cenários e estamos impossibilitados dessa convivência, neste momento da pandemia, o que nos direcionam a propositar outros desenhos didáticos para a formação para a docência considerando o ensino remoto, não presencial para a oferta dos estágios supervisionados nos cursos de licenciatura.

A condição constitutiva da docência em formação inicial é um desenho com a imagem de três sujeitos em papeis discursivos e atribuições historicamente reconhecidas e assentadas no imaginário social da escola: o professor formador/o professor supervisor/o licenciando. Essa condição (re) compõe o campo de trabalho e profissionalização, o que, no contexto de suspensão de aulas presenciais, contrapõe-se à imersão na escola de educação básica, espaço natural de ocorrência das práticas de ensino na sala de aula pelo estagiário.

O que se vislumbra na fragmentação dessa condição é a fragilidade da formação profissional. Contudo, nova arquitetura didática se projeta, no espaço virtual do ensino remoto, como configuração possível de se garantir a tríade formativa e dialógica específica do componente curricular no formato de estágio remoto não presencial, argumentando-se por mobilizar a etnografia virtual para olhar e interpretar os objetos da docência, a fim de facultar essa experiência aos estudantes em formação inicial. Para motivar essa investida, tomamos o pensamento bakhtiniano como inspiração:

O princípio arquitetônico supremo do mundo real do ato é a contraposição concreta, arquitetonicamente válida, entre eu e outro. [...] Esta divisão arquitetônica do mundo em eu e em todos aqueles que para mim são outros não é passiva e causal, mas ativa e imperativa [...] Essa não é dada como uma arquitetônica pronta e consolidada [...] mas é o plano ainda-por-se-realizar 
[zadannyi], da minha orientação no existir-evento, uma arquitetônica incessantemente e ativamente realizada por meu ato responsável, edificada por meu ato e que encontra a sua estabilidade somente na responsabilidade do meu ato (BAKHTIN, 2010, p.142-143).

A docência é um cenário discursivo de trocas interativas e, no espaço virtual, envolve atividades, síncronas e assíncronas de produção do conhecimento escolar. Na nossa argumentação, o estágio é uma das realizações da docência. É uma atividade específica intrinsecamente articulada com a prática e com as demais atividades da profissionalização, como já referenciado. Enseja-se uma reelaboração que a absorva como prática discursiva, conforme se transcreve:

Nessa prática discursiva da docência, a posição eu-para-mim (de professor de) abriga a memória das representações históricas do magistério (do grupo social), de um certo modo de agir. Não obstante, caracteriza-se como um lugar único e sempre novo, irrepetível, em que cada um (estagiário) assume sua posição de professor, cada qual se relaciona com o outro (aluno - indivíduo, coletivo). É, pois, um trabalho de um profissional em que um eu singular (posição de "o professor de"; o "fulano") se volve para o outro (aluno (s) - indivíduo; coletividade (a turma)) (BORTOLOTTO; FIAD, 2017, p.10).

Sobre ensino remoto sublinha-se a pertinência de se estabelecer o convívio entre processos presenciais e não presenciais de atividades curriculares, contudo, no específico da pandemia, esse se realizaria como não presencial, em ambiente virtual. Essa configuração não se espelha como a oferta de educação a distância, vez que essa requer um design de aprendizagem que favoreça a interação online de construção de conhecimento escolar e aprendizagem, bem como de registro dos conteúdos, tarefas e monitoramento pelo docente, além de, em alguns formatos, a ocorrência de encontros presenciais em polos de apoio.

Não podíamos imaginar que seríamos tão violentamente atingidos pela Coronavírus. O espaço público de nossas vidas, e em especial, das escolas foi abortado de nosso cotidiano. Enquanto profissionais e estudantes, a vida nas escolas teve que se reconfigurar perante um uma tela de computador ou outro equipamento. Como professores e estudantes somos incumbidos a remodelar as práticas para a continuidade da oferta escolar por meio do ensino remoto. As universidades enfrentaram os problemas decorrentes da desigualdade de acesso e condições para a inclusão digital, a ausência de formação para o domínio das diferentes práticas digitais, além de aspectos estruturais e de gestão do conhecimento.

Moreira, Henriques e Barros (2020) contextualizam esse panorama: 
Com efeito, a suspensão das atividades letivas presenciais, por todo o mundo, gerou a obrigatoriedade dos professores e estudantes migrarem para a realidade online, transferindo e transpondo metodologias e práticas pedagógicas típicas dos territórios físicos de aprendizagem, naquilo que tem sido designado por ensino remoto de emergência. E na realidade, essa foi uma fase importante de transição em que os professores se transformaram em youtubers gravando vídeoaulas e aprenderam a utilizar sistemas de videoconferência, como o Skype, o Google Hangout ou o Zoom e plataformas de aprendizagem, como o Moodle, o Microsoft Teams ou o Google Classroom. No entanto, na maioria dos casos, estas tecnologias foram e estão sendo utilizadas numa perspectiva meramente instrumental, reduzindo as metodologias e as práticas a um ensino apenas transmissivo. É, pois, urgente e necessário transitar deste ensino remoto de emergência, importante numa primeira fase, para uma educação digital em rede de qualidade (MOREIRA; HENRIQUES, BARROS, 2020, p. 352).

Nesse contexto de problematizações, nos inclinamos a considerar a possibilidade de ofertar o estágio supervisionado dos cursos de licenciatura por meio do ensino remoto, desde que se preserve a seguinte arquitetura curricular:

a) realização de aulas on-line com o grupo de estagiários para planejamento e elaboração da proposta de estágio;

b) formação para uso de ambiente digital, tanto para licenciandos, como para docentes;

c) realização de encontros virtuais com o (a) professor (a) da educação básica para apresentação e ajustes necessários à proposta de estágio;

d) retomada das atividades de ensino na escola da educação básica, com garantia de acesso à tecnologias envolvidas nas práticas de ensino remoto, participação e frequência dos estudantes da educação básica.

e) garantia de acesso e inclusão digital.

Compreende-se que, se preservada a tríade exigida para a materialização do estágio, na sua compreensão de atividade supervisionada e monitorada por docente da educação superior e da educação básica, oportuniza-se ao estudante a vivência no tempo/espaço virtual da aula remota, ancorada na etnografia virtual.

Sarmento, Rocha e Paniago (2019) nos informam que:

O Estágio, segundo a literatura científica da área de formação de professores, constitui um momento fecundo para a construção da identidade e para os saberes e práticas da docência. É no encontro com as diversas situações do cotidiano da escola, seja em sala de aula, seja no diálogo com os professores e/ou participação nas atividades de planejamento, reuniões, oficinas, que os estagiários vão construindo a sua identidade docente bem como aprendizagens que serão mobilizadas enquanto futuros professores. Estas aprendizagens perspectivam-se 
em práticas formativas que fomentam a reflexão, o questionamento e a investigação com vistas a estudar, analisar, problematizar, enfim, a desenvolver projetos de intervenção envolvendo as relações e práticas heterogêneas do contexto escolar da educação básica. (SARMENTO, ROCHA, PANIAGO, 2019, p 153).

Como o antigo planejamento e currículo da escola não se sustentam no contexto da COVID19, novo aporte de formação teórica e metodológica é requerido para o plano de estágio por meio do ensino remoto. As estratégias a serem desenvolvidas e o domínio dos recursos para suporte da aula devem ser considerados na seleção de tópicos do conteúdo das disciplinas sob responsabilidade do estagiário. Partimos da premissa de que, como professor formador, estamos, nas universidades, trabalhando por meio de ensino remoto, e os estabelecimentos da educação básica retornaram o calendário letivo com a adoção de atividades remotas e não presenciais, portanto, esse acontecimento do continuum da formação docente, que nos assolou no ano de 2020 (e talvez persista) pode ser tomado como instância de produção de conhecimento sobre a docência, na singularidade do ensino remoto.

Há de se considerar dois espaços para a realização do estágio nessa proposição: a sala de aula virtual/online e o espaço casa. A primeira é um espaço colaborativo de construção de conhecimentos sobre a docência para o professor em formação inicial e espaço ativo de apropriação de conteúdos disciplinares pelos estudantes da educação básica. O espaço casa é destinado ao estudante da educação básica, que, a partir de um bloco de tarefas complementam a sua formação em tempo horário, mediante plano de estudos ofertado e elaborado sob a supervisão dos demais sujeitos formadores envolvidos no desenho pedagógico do estágio supervisionado remoto. É possível, assim, o exercício da docência, na sua acepção de práticas de ensino remoto, diversificada nos gêneros escolares aula, tarefas didáticas, seminários, dentre outros para o domínio da profissão professor.

As proposições para a oferta do estágio supervisionado que, até o momento, temos conhecimento no contexto da COVID19, abdicam do tempo espaço da aula virtual, bem como da convivência com o professor da educação básica, denominado como professor regente, e da interação estagiário campo de estagio. Essas proposições aglutinam-se em:

1. Bloco de atividades integrantes do currículo do curso de licenciatura: neste bloco, as atividades já se encontram ou já foram realizadas pelos estudantes, sem a participação do professor formador e compõe-se de:

- atividades alicerçadas em projetos de extensão 
- atividades alicerçadas em projeto de pesquisa

- atividades alicerçadas em monitoria didática

2. Bloco de atividades relacionadas à experiência profissional já adquirida: neste bloco, consideram-se a experiência pregressa do licenciando, enquanto profissional que já atuou ou atua na educação básica, em disciplina específica ao curso ou distinta da área de formação, a saber:

- prática profissional de ensino na educação básica no próprio local de trabalho do estudante professor

- prática profissional de ensino na educação básica prévia ao ingresso no curso de licenciatura

3. Bloco de atividades atualização e formação docente: neste bloco, considera-se o cômputo de carga horária de cursos extracurriculares, já cursados ou cursados ao longo do curso, na modalidade presencial ou EAD, relacionados às metodologias de ensino ou tópicos específicos da docência.

\section{Bloco de elaboração de materiais de suporte à aprendizagem}

Criação de atividades e propostas didáticas que possam ser aplicadas no espaço casa, pelos responsáveis ou realizadas pelo próprio estudante, na consideração de sua autonomia de gestão do tempo e aprendizagem escolar, que priorizem a aprendizagem de tópicos dos conteúdos escolares.

\section{Bloco de Atividades de Ensino externo ao campo da profissionalização}

- Elaboração de planos de aulas, sequências didáticas e projetos de ensino, sob orientação do professor da disciplina.

- Elaboração de materiais didáticos para uso em contextos de ensino remoto;

- Produção de lives, webnários e de outros gêneros online, enfocando tópicos da disciplina.

Além desses blocos, ainda, se encontram proposições relacionadas à pesquisa e extensão, sendo orientado estudo de caso, pesquisa de base documental, autobiográficas, cartografias docentes, projetos de extensão por meio de encontros virtuais com profissionais da educação básica e gestores escolares.

Nosso argumento é o de que o estágio supervisionado formatado como ensino remoto potencializa a vivência etnográfica no ambiente virtual, bem como a interação professor formador/supervisor/estagiário no contexto da educação básica. O parecer CNE/CP 05/2020, orienta, no que concerne à educação superior, "a reinterpretar os limites de aulas e outras atividades acadêmicas que podem ser ofertadas a distância" (BRASIL, 2020, p. 16) e, ainda, ao 
abordar o estágio nas licenciaturas, mesmo facultando a sua realização em práticas extensionistas e de pesquisa, sublinha que:

No caso dos cursos de licenciatura ou formação de professores, as práticas didáticas vão ao encontro de um amplo processo de oferta de aprendizado não presencial à educação básica, principalmente aos anos finais do ensino fundamental e médio. Produz, assim, sentido que estágios vinculados às práticas na escola, em sala de aula, possam ser realizados de forma igualmente virtual ou não presencial, seja a distância, seja por aulas gravadas etc. (BRASIL, 2020, p. 16).

Ao mesmo tempo cabe reiterar a autonomia das universidades para recomposição dos seus projetos pedagógicos em decorrência das contingências do estado de emergência sanitária decorrente da COVID-19, podendo reorganizar o calendário letivo e modalidade de oferta das disciplinas:

Quanto às atividades práticas, estágios ou extensão, estão vivamente relacionadas ao aprendizado e muitas vezes localizadas nos períodos finais dos cursos. Se o conjunto do aprendizado do curso não permite aulas ou atividades presenciais, seria de se esperar que, aos estudantes em fase de estágio, ou de práticas didáticas, fosse proporcionada, nesse período excepcional da pandemia, uma forma adequada de cumpri-lo a distância. (BRASIL, 2020, p. 17).

A experiência escolar é dependente do ambiente pedagógico da e na escola, é basilar para assentar a conceituação sobre os estágios. A cultura escolar possui seus ritmos, ritos e rotinas materializados no contexto de ensino presencial e, de imediato, o que precisa ser desconstruído é o mito da transposição desse cenário para o ensino remoto, tentativa infrutífera, porque os elementos rotineiros são próprios da instituição escola. Feita a opção pelo ensino remoto, não presencial, uma pergunta se impõe: é possível, nas condições que temos, garantir acesso digital e igualdade todos os estudantes? A educação como direito, no cenário da pandemia, é dependente do atendimento a essa questão.

\section{CONSIDERAÇOES FINAIS}

Enquanto docentes, nos reinventamos para garantir o direito à educação aos nossos estudantes nesse contexto da pandemia. Medidas de distanciamento social e de isolamento infiltraram-se no nosso cotidiano doméstico e profissional e é a orientação científica para preservar a vida, enquanto não ocorre a imunização. Um horizonte incerto, quanto ao retorno presencial da 
vida nas escolas, impõe a busca e aplicação de estratégias para retorno às aulas, ainda que em formatos não presenciais ou online.

A ausência da vivência na escola na condição de estagiário e como instituição formadora e educativa é uma catástrofe para nossas vidas em sociedade. Grande parte da população brasileira encontra na escola, além do direito à educação, o direito à vida, à seguridade e proteção social, além de constituição de vínculos afetivos que (podem) perdurar por toda vida social do sujeito estudante ou professor.

Desde meados de março, a suspensão da oferta às aulas é uma realidade nacional. Em 20 de março de 2020, data em que foi decretado o estado de calamidade pública no Brasil, a restrição da aprendizagem é sentida por milhões de estudantes, em especial, da rede pública de ensino e a necessidade de formação em ambiente textual é um mote para a docência; portanto, se faz necessário apropriar-se de práticas pedagógicas para melhorar desenvolver o exercício da docência, visto que, neste momento, fomos confrontados com os limites do ensino presencial.

Como já referimos na introdução deste texto, a nossa intenção foi apresentar, de forma muito resumida, desenhos didáticos para a realização do estágio supervisionado remoto que preserve a tríade de sujeitos institucionais que o sustenta, bem como o exercício profissional na escola da educação básica. A vivência com os pares da formação, a interação simétrica com os colegas de estágio do ensino universitário e as interações assimétricas com alunos e profissionais de escolas de educação básica são remodeladas para o ambiente virtual.

Os projetos pedagógicos dos cursos foram assentados na realização do estágio presencial e, abruptamente, as instituições, são convocados a se organizarem para atender o retorno não presencial. Assim, também, os deslocamentos para a organização do estágio em ensino remoto é uma realidade que se impõe, na observância das reais condições materiais para sua realização, nas esferas da formação docente para orientar e atuar no contexto não presencial.

Outro aspecto a se considerar é que o perfil dos licenciandos tem se alterado ao longo dos anos. Até final do século XX, as turmas dos cursos de licenciatura eram constituídas por professores estudantes, e, em tempo mais recente, temos os estudantes sem a experiência profissional da docência. A maioria das (os) licenciandos não se reconhece na "regência de uma sala de aula." Assim, a imersão no campo do estágio, na sala de aula, quer virtual, quer presencial, é um indicador que favorece a formação técnica, afetiva e profissional.

No entanto, temos plena consciência de que a proposição contida neste texto não pode ser interpretada como única via para a realização dos estágios supervisionadas no cenário da Pandemia, 
mas, não podíamos, ante a nossa filiação teórica, abdicar de reconhecer os processos polifônicos de formação para a docência no tecido da cultura escolar, assim convocados à docência online e ao ensino remoto, como mais uma lente de nosso percurso formativo, no entendimento de que, dentre tantos desafios, o ensino remoto não é transposição do ensino presencial.

\section{REFERÊNCIAS}

ARAÚJO, Osmar Hélio Alves; MARTINS, Elcimar Simão. Estágio curricular supervisionado como práxis: algumas perguntas e possíveis de respostas. Reflexão e Ação. Santa Cruz do Sul, v. 28, n. 1, p. 191-203, jan/abr. 2020. DOI http://dx.doi.org/10.17058/rea.v28i1. Disponível em:

https://online.unisc.br/seer/index.php/reflex/article/view/12902/pdf. Acesso em: 21 jul. 2020.

ARAÚJO, Osmar Hélio Alves. O estágio como práxis, a pedagogia e a didática: que relação é essa?

Revista Eletrônica de Educação, v. 14, 1-15, e3096048, jan./dez. 2020. DOI

http://dx.doi.org/10.14244/198271993096. Disponível em:

http://www.reveduc.ufscar.br/index.php/reveduc/article/view/3096/931. Acesso em: 21 jul. 2020.

AROEIRA, Kalline Pereira; PIMENTA, Selma Garrido (Orgs.). Didática e Estágio. Curitiba: Aprris, 2018.

BAKHTIN, Mikhail. Para uma filosofia do ato responsável. Tradução aos cuidados de Valdemir Miotello e Carlos Alberto Faraco. São Carlos: Pedro e João Editores, 2010.

BARRETO, Edna Silva; OLIVEIRA, Maria Marly de; ARAÚJO, Mônica Lopes Folena. O Estágio Supervisionado Obrigatório na formação do professor de Ciências e Biologia: perspectivas de licenciandos e orientadores. Revista Tempos e Espaços em Educação, Aracajú, v. 8, n. 16, maio/ago. 2015. Disponível em: https://seer.ufs.br/index.php/revtee/article/view/3951. Acesso em: 29 de agosto de 2020 .

BORTOLOTTO, Nelita; FIAD, Raquel Salek. O espaço público da escola - um mundo significado nas relações eu outro. Bakhtiniana, São Paulo, 12 (3): 5-21, Set./Dez. 2017. DOI

http://dx.doi.org/10.1590/2176-457330649. Disponível em:

https://www.scielo.br/pdf/bak/v12n3/2176-4573-bak-12-03-0005.pdf. Acesso em: 21 jul. 2020.

BRASIL. Lei no 9.394, de 20 de dezembro de 1996. Estabelece as diretrizes e bases da educação nacional. Brasília, 1996. Disponível em: http://www.planalto.gov.br/ccivil 03/leis/19394.htm. Acesso em: 08 de maio de 2019.

BRASIL. Resolução CNE/CP no 2, de 19 de fevereiro de 2002. Institui a duração e a carga horária dos cursos de licenciatura, de graduação plena, de formação de professores da Educação Básica em nível superior. Brasília, 2002. 
BRASIL. Resolução CNE/CP no 1, de 18 de fevereiro de 2002. Institui Diretrizes Curriculares Nacionais para a Formação de Professores da Educação Básica, em nível superior, curso de licenciatura, de graduação plena. Brasília, 2002a.

BRASIL. Resolução CNE/CP no 2, de 01 de julho de 2015, define as Diretrizes Curriculares Nacionais para a formação inicial em nível superior (cursos de licenciatura, cursos de formação pedagógica para graduados e cursos de segunda licenciatura) e para a formação continuada. Diário Oficial da União, Brasília, DF, 2 jul. 2015.

BRASIL. Ministério da Educação. Conselho Nacional de Educação. Parecer CNE/CP 5, de 28 de abril de 2020. Reorganização do Calendário Escolar e da possibilidade de cômputo de atividades não presenciais para fins de cumprimento da carga horária mínima anual, em razão da Pandemia da COVID-19. Brasília: DF, 2020. D.O.U. de 01/06/2020, Seção 1, Pág. 32.Disponível em:

http://www.in.gov.br/en/web/dou/-/despacho-de-29-de-maio-de-2020-259412931. Acesso em: 31 de maio de 2020.

BRITO, Regivane dos Santos; PRADO, Jany Rodrigues; NUNES, Claudio Pinto. As condições de trabalho docente e o pós-estado de bem-estar social. Revista Tempos e Espaços em Educação (online), v. 10, p. 165-174, 2017. Disponível em:

https://seer.ufs.br/index.php/revtee/article/view/6676. Acesso em: 21 fev. 2020.

CARROLO, Carlos. Formação e identidade profissional de professores. In: ESTRELA, Maria Teresa (org.). Viver e construir a profissão docente. Lisboa: Porto Editora, 1997. p. 21-50.

COSTA, Ana Sheila Fernandes; AKKARI, Abdeljalil; SILVA, Rossana Valéria Souza. Educação básica no Brasil: políticas públicas e qualidade. Revista Práxis Educacional, Vitória da Conquista, v.7, n. 11, jun./dez. 2011. Disponível em: http://periodicos2.uesb.br/index.php/praxis/article/view/666. Acesso em: 14 fev. 2020.

FRANCO, Maria Amélia do Rosário Santoro; GILBERTO, Irene Jeanete Lemos. O observatório da prática docente como espaço de compreensão e transformação das práticas Revista Práxis Educacional, Vitória da Conquista, v. 6, n. 9, jul./dez. 2009. Disponível em:

http://periodicos2.uesb.br/index.php/praxis/article/view/637. Acesso em: 30 de agosto de 2020.

FREIRA, Maria Auxiliadora S. Práxis pedagógica e professores intelectuais: refletindo as tensões e concepções da formação/prática docente. Revista Práxis Educacional, Vitória da Conquista, v.1, n. 1, jan./dez. 2005. Disponível em: http://periodicos2.uesb.br/index.php/praxis/article/view/485. Acesso em: 13 fev. 2020.

GOMES, Marineide de Oliveira (Org.). Estágios na formação de professores: Possibilidades formativas entre ensino, pesquisa e extensão. São Paulo: Edições Loyola, 2011.

MOREIRA, José António Marques; HENRIQUES, Susana; BARROS, Daniela. Transitando de um ensino remoto emergencial para uma educação digital em rede, em tempos de pandemia.

Dialogia, São Paulo, n. 34, p. 351-364, jan./abr. 2020. DOI

https://doi.org/10.5585/dialogia.n34.17123. Disponível em:

https://periodicos.uninove.br/index.php?journal=dialogia\&page=article\&op=view\&path\%5B\%5D= 17123\&path\%5B\%5D=8228. Acesso em: 14 ago. 2020. 
NASCIMENTO, L. F.; CAVALCANTE, M. M. D. Abordagem quantitativa na pesquisa em educação: investigações no cotidiano escolar. Revista Tempos e Espaços em Educação, v. 11, n. 25, p. 249260, 29 mar. 2018. Disponível em: https://seer.ufs.br/index.php/revtee/article/view/7075 Doi: https://doi.org/10.20952/revtee.v11i25.7075

NUNES, Claudio Pinto. Formación y trabajo docente: cuestiones contemporáneas. Revista Êxitus, Santarém, v. 9, n. 1, 2019. Disponível em:

http://www.ufopa.edu.br/portaldeperiodicos/index.php/revistaexitus/article/view/917. Acesso em: 18 fev. 2020.

NUNES, Claudio Pinto; OLIVEIRA, Dalila Andrade. Trabalho, carreira, desenvolvimento docente e mudança na prática educativa. Educação e Pesquisa, São Paulo, v. 43, p. 65-80, 2017. Disponível em: https://www.scielo.br/scielo.php?pid=S1517-

97022017000100066\&script=sci abstract\&tlng=pt. Acesso em: 20 fev. 2020.

PARASKEVA, J. M. "Brutti, Sporchi \& Cattivi": Towards a Non-Abyssal Curriculum. Revista Tempos e Espaços em Educação, v. 9, n. 18, p. 75-90, 2016. Disponível em: https://seer.ufs.br/index.php/revtee/article/view/4966 Doi: https://doi.org/10.20952/revtee.v9i18.4966

PICONEZ, Stela C. B. A prática de ensino e o estágio supervisionado. 24 ed. Campinas, SP: Papirus, 2012.

PIMENTA, Selma Garrido; LIMA, Maria Socorro Lucena. Estágio e Docência. 6 ed. São Paulo: Cortez, 2011.

SANTOS, Cláudia Santana; GIVIGI, Rosana Carla do Nascimento. Contribuições das funções sociais do professor na construção do ser profissional. Revista Tempos e Espaços em Educação. v.13, n. 32, e-13304, jan./dez.2020. DOI https://doi.org/10.20952/revtee.v13i32.13304. Disponível em: https://seer.ufs.br/index.php/revtee/article/view/13304/10378. Acesso em: 19 ago. 2020.

SANTOS, Patrícia Ferreira dos; COSTA, Váldina Gonçalves da; PEREIRA, Diego Carlos. Registros nos cadernos de estágio supervisionado: contribuições para a constituição da identidade profissional docente. Revista Tempos e Espaços em Educação, Aracajú, v. 11, n. 27, out./dez. 2018. Disponível em: https://seer.ufs.br/index.php/revtee/article/view/7200. Acesso em: 29 de agosto de 2020.

SILVA, Nilson Robson Guedes. Gestão escolar democrática: uma contextualização do tema. Revista Práxis Educacional, Vitória da Conquista, v. 5, n. 6, jan./jun. 2009. Disponível em:

http://periodicos2.uesb.br/index.php/praxis/article/view/590. Acesso em: 13 fev. 2020.

SOUSA, J. M. Repensar o currículo como emancipador. Revista Tempos e Espaços em Educação, v. 9, n. 18, p. 111-120, 11 abr. 2016. Disponível em:

https://seer.ufs.br/index.php/revtee/article/view/4969. Acesso em: 29 de agosto de 2020.

SOUZA, Ester Maria de Figueiredo Souza. O estágio supervisionado no curso de licenciatura em Letras: impactos da resolução CNE/CP № 1/2002 e no 2/2002. In: LEITE, Maria Iza Pinto de Amorim, et alii. Docência: Gestão, ensino e pesquisa. Vitória da Conquista: Edições UESB. 2010. 
SOUZA, Ester Maria de Figueiredo Souza. Linguagem, currículo, formação docente. Vitória da Conquista: Edições UESB. 2011.

SOUZA, Ester Maria de Figueiredo Souza. MARTINS, Angela Maria Gusmão Santos. Estágio supervisionado nos cursos de licenciatura: pesquisa, extensão e docência. Revista Práxis Educacional, Vitória da Conquista, Bahia, Brasil, v. 8, n. 13, p. 143-156, 2012. Disponível em: http://periodicos2.uesb.br/index.php/praxis/article/view/711/597. Acesso em: 03 abr. 2015.

SOUZA, Ester Maria de Figueiredo Souza. FERREIRA, Lúcia Gracia. A prática como componente curricular: (re)indagações para a formação docente. Revista Práxis Educacional, Vitória da Conquista, Bahia, Brasil, v. 15, n. 34, p. 195-210, Edição Especial, 2019. DOI https://doi.org/10.22481/praxisedu.v15i34.5505A. Disponível em: http://periodicos2.uesb.br/index.php/praxis/article/view/5505/4183 . Acesso em: 29 nov. 2019.

SARMENTO, Teresa; ROCHA, Simone Albuquerque da; PANIAGO Rosenilde Nogueira. Estágio curricular: o movimento de construção identitária docente em narrativas de formação. Revista Práxis Educacional, Vitória da Conquista - Bahia - Brasil, v. 14, n. 30, p. 152-177, out./dez. 2018. DOI https://doi.org/10.22481/praxis.v14i30.4365. Disponível em:

http://periodicos2.uesb.br/index.php/praxis/article/view/4365/3493. Acesso em: 05 mar. 2019.

\section{SOBRE AS AUTORAS}

\section{Ester Maria de Figueiredo Souza}

Doutorado em Educação pela Universidade Federal da Bahia (UFBA). Pós-Doutorado em Linguística pela Universidade de Brasília (UNB). Professora Plena da Universidade Estadual do Sudoeste da Bahia (UESB). Docente dos cursos de Letras Vernáculas e Modernas, do Programa de Pós-graduação em Educação (PPGED), do Programa de Pós-graduação em Letras (PPGCEL) da UESB. Líder Grupo de Pesquisa Linguagem e Educação/UESB.

E-mail: efigueiredo@uesb.edu.br

ORDID: http://orcid.org/0000-0001-5992-0184

\section{Lúcia Gracia Ferreira}

Doutora em Educação pela Universidade Federal de São Carlos (UFSCar). Pós-doutorado pela Universidade Federal da Bahia (UFBA) e Universidade Estadual do Sudoeste da Bahia (UESB). Professora da Universidade Federal do Recôncavo da Bahia (UFRB) e da Universidade Estadual do Sudoeste da Bahia-Itapetinga (UESB). Professora do Programa de Pós-Graduação em Educação da Universidade Federal da Bahia; Grupo de Pesquisa e Estudos Pedagógicos/UESB e Docência, Currículo e Formação/UFRB.

E-mail: luciagferreira@ufrb.edu.br

Orcid: http://orcid.org/0000-0003-3655-9124 
Aprovado em: 24/08/2020 Publicado em: 04/10/2020 